\title{
Notas sobre pesquisa colaborativa com sacerdotisas da Deusa Iyami Osoronga ${ }^{\star}$
}

\author{
Silvia Barbosa de Carvalho, ${ }^{(D)}$ Samira Lima da Costa, ${ }^{(D)}$ Andréa Coelho Ferreira \\ Universidade Federal do Rio de Janeiro, Rio de Janeiro, RJ, Brasil
}

\section{Resumo}

A ciência hegemônica, pautada em referenciais coloniais, traça linhas bem definidas entre o eu e o outro da pesquisa. Ao lançar foco sobre as tradições de matriz africana, estas linhas são reforçadas com as cores do racismo, seja na expressão das desigualdades como naturais desta divisão, seja na ratificação de um lugar subalterno, pela desqualificação dos saberes da população negra, desde a escravização. Ainda que este cenário produza imensas desigualdades, ao longo da história os povos tradicionais vêm resistindo, pela manutenção de suas tradições, na produção de valores contracoloniais. Este trabalho visa apresentar os caminhos de uma pesquisa colaborativa, em parceria com as sacerdotisas de uma sociedade secreta de culto à deusa Iyami Osoronga. Pensada a partir do campo da psicossociologia, tem como referencial os estudos de memória, tradição, discursos pós e decoloniais e os estudos culturais. A pesquisa colaborativa tem o intuito de propor, não um desenho de pesquisa focada em uma ou outra teoria, como posicionamento de uma construção especifica, singular, dependente direta de suas autoras e de múltiplos fatores, mas levando à reflexão sobre autoria, saberes e fazeres de epistemologias contra-hegemônicas, que pensam e falam "com" e não "de" ou "para" seus "objetos" de pesquisa.

Palavras-chave: saberes tradicionais; epistemologias contra-hegemônicas; pesquisa colaborativa; psicossociologia.

\section{Notes on collaborative research with priestesses of the Goddess Iyami Osoronga}

\begin{abstract}
The hegemonic science based on colonial references draws well defined lines between the self and the other of the research. In the case of the African matrix traditions, these lines are reinforced with the colors of racism, either in the expression of the inequalities as natural of this division, or in the ratification of a subaltern place, by the disqualification of the knowledge of the black population, from enslavement. Although this scenario produces immense inequalities, throughout the history, the traditional people have been resisting, by the maintenance of their traditions, in the production of contracolonials values. This work aims to present the ways of a collaborative research, in partnership with the priestesses of a society secret cult of the goddess Iyami Osoronga. Based on the field of psycho-sociology, with reference to studies of memory, tradition, discourses after and decolonials and cultural studies with reference to studies of memory, tradition, discourses after and decolonials and cultural studies with the purpose of proposing, not a research design focused on one or another theory, but the search for the positioning of a specific construction, unique, direct dependence of its authors and of multiple factors, leading to the reflection on authorship, knowledge and practices of epistemologies against hegemonic, the speak "with" and "for" and not "of" their "objects" of research.
\end{abstract}

Keywords: traditional knowledge; against hegemonic epistemologies; collaborative research; psichosociology.

\section{Introdução}

Refletir sobre o desenvolvimento das ciências sociais e suas implicações com os grupos a que se dedicam tem sido uma constante nos fazeres da pesquisa social. Essas implicações envolvem diferentes fatores que, se por um lado garantem a ampliação de seus campos, por outro trazem à tona de modo cada vez mais contundente os desafios de uma pesquisa engajada, em que os grupos, na condição de participantes, já não se submetem às simplificações do lugar de "objeto de estudos". Ao contrário, cada vez mais estes grupos denunciam os olhares e práticas reducionistas e apresentam-se como produtores de conhecimento; os participantes, produzindo saberes contra-hegemônicos e reflexões profundas sobre a academia, fazendo uma críti-

\footnotetext{
$\star \mathrm{O}$ presente texto é parte da pesquisa de doutorado, com financiamento próprio, em andamento no EICOS/IP/UFRJ e que tem como título: O Mundo e seus mundos: poder feminino, memória e tradição entre mulheres da sociedade Iyami Osoronga no Rio de Janeiro, da UFRJ e parte da linha de investigação de pós-doutorado sobre Saberes e ocupações tradicionais no Estado do Rio de Janeiro, da UNB.

$\star \star$ Endereço para correspondência: Universidade Federal do Rio de Janeiro,

Divisão de Saúde do Trabalhador, Coordenação de Políticas de Saúde do Trabalhador. Rua Maurício Joppert de Silvauza - Cidade Universitária - Rio de Janeiro, RJ - Brasil. CEP: 21941972.E-mails: sbcarvalho6@hotmail.com, biasam2000@gmail.com, andrea.coe@hotmail.com

Os dados completos das autoras encontram-se ao final do artigo.
}

ca a seus mecanismos de produção de atribuição de legitimidade científica, que excluem os saberes tradicionais ou a eles se voltam como elementos objetificados.

Apresentaremos aqui um pouco da trajetória de produção de conhecimentos de modo colaborativo (BANDEIRA et al., 2016) em uma pesquisa de doutoramento que se dedica ao estudo do segredo, a partir das memórias das sacerdotisas do culto a Iyami Osoronga, desde a aproximação do grupo até os percalços na produção de um caminho de pesquisa onde pudesse vir à tona a voz dessas mulheres, não como contribuição no contorno ou afirmação da voz das sacerdotisas, mas como proposição de um modo de ser pesquisador(a) que fosse pertinente e fizesse sentido para todos os envolvidos no processo. Trata-se de apresentar um caminho que garantisse trazer à tona a potência deste encontro da academia com o saber tradicional de matriz africana. Neste percurso, nossas mãos se encontraram para fazer, bem no passo a passo, uma possibilidade de caminho. 


\section{Ciência e produção de saberes contra-hegemônicos}

O desenvolvimento da psicologia como ciência contou com a busca de ambientes bem delimitados de atuação, visando consolidar processos e percursos específicos que definiram campos de pesquisas e seus modelos correlatos, garantindo a hegemonia de seus projetos. Ainda que contasse com o empenho de muitos profissionais comprometidos com a ética de seus fazeres e muito tenha se desenvolvido em seus campos de atuação, não podemos desconsiderar sua trajetória como ciência pautada nos paradigmas da ciência hegemônica, que define campos, saberes, interesses, métodos e metodologias de pesquisa pautados na dicotomia do centro e periferia, do eu e do outro, do negro e do branco (CARONE, 2012).

Se este foi o cenário da constituição das ciências sociais, não podemos esperar que estes modelos ainda hoje possam ser replicados, sem refletir sobre as complexidades do mundo contemporâneo. A pesquisa colaborativa aqui apresentada subverteu este modelo de leitura de mundo, estabelecendo objetivos comuns construídos com o grupo de sacerdotisas, rompendo a equação clássica "pesquisador" e "sujeitos de pesquisa". A proposta inicial foi valorizar as vozes de mulheres que têm no segredo um modo de resistência de suas histórias e memórias. Ao longo do percurso o objetivo foi se redesenhando, passando a refletir questões das sacerdotisas, interessadas em conhecer como Iyami e elas próprias, suas sacerdotisas, são vistas pelos membros do terreiro. Em um mundo cujas fronteiras são fluidas, é cada vez mais evidente e necessária a proliferação de expressões de múltiplos grupos, denunciando que os poderes já não se encontram sob o domínio de um, mas mostra-se como um poder dividido (NEGRI; COCCO, 2005).

Séculos depois do fim da escravização, há muito a ser discutido nos campos da psicologia e da sociologia sobre os modelos com os quais nos dedicamos a pensar seus efeitos (SINHORETO; MORAIS, 2018). Neste embate é cada vez mais evidente que a pauta de uma produção de conhecimentos contra-hegemônicos caminha em parceria direta e respaldada pelos interesses desses grupos. Assim, a academia tem seus referenciais relativizados, foco na crítica de outros modos de produção de conhecimento que se colocam em posição de igualdade, com suas experiências e saberes tradicionais (COSTA, 2018).

\section{A Sociedade Osoronga como expressão de resistência feminina - o contexto da pesquisa}

A cosmovisão ioruba, da nação Kétu, presente nas comunidades de terreiro, reverencia os Orisa(s) coletivos (deuses e deusas) e seus ancestrais familiares. A combinação destas forças desenha um sistema explicativo do mundo e seus acontecimentos, passados e futuros, a partir das divindades. A harmonia entre o Orun, mundo superior, do terreno espiritual; e o Aiyê, mundo físico no qual nascemos, vivemos e morremos (VERGER, 1996; BENISTE, 1997) dá-se pela manutenção de práticas de adoração e ritos. Na África, Iyami Osoronga representa o culto aos ancestrais femininos por meio da sociedade
Gèlèdè e da sociedade Egbé, à semelhança da sociedade Egungun, de culto aos Eguns masculinos (OGBEBARA, 2006; BENISTE, 1997).

Com a diáspora forçada, houve o desmantelamento desses sistemas rituais, bem como a possibilidade de culto aos ancestrais familiares, estas últimas, reconfiguradas em sociedades secretas, como é o caso da Sociedade Osoronga, que cultua Iyami Osoronga, considerada como a mãe de todos, útero do mundo, a terra. A deusa é temida como poderosa feiticeira, capaz de realizar as maiores façanhas por meio de feitiços poderosos (VERGER, 1994; SANTOS, I., 2008). Seus ensinamentos secretos são transmitidos apenas às mulheres convocadas pela deusa para cultuá-la, e suas histórias são contadas e recontadas, enaltecendo seus feitos e ratificando os poderes de suas sacerdotisas, as Iyalode(s).

$\mathrm{O}$ poder de Iyami Osoronga, ofertado às suas sacerdotisas, proporciona feitos grandiosos; poder avassalador e incontrolável que, mal administrado, pode ser fatal (GOMES, 2015; MANZINI, 2001; SANTOS, I., 2008; VERGER, 1994). Seus mitos aparecem como elemento norteador das relações dos grupos, seja por sua manutenção pela transmissão oral em muitos rituais, seja por retroalimentar o sistema de regulação dos grupos com sua dinâmica exemplar, mantendo o status quo de suas sacerdotisas. Seus poderes se ratificam pelos saberes e crenças do grupo social por meio da manutenção da memória e da tradição, atualizando a fé e a coesão do grupo em torno de uma crença comum.

Para alguns autores, a complexidade do culto a Iyami Osoronga está ligada ao medo da força intrínseca à natureza feminina, própria das religiões matrilineares (SANTOS I., 2008; VERGER, 1996; OGBEBARA, 2006). O culto apresenta-se como narrativas de resistência das mulheres, que no cenário de escravização contribuiu para a sobrevivência e saúde dos povos tradicionais (CANCLINI, 2000), levando à reflexão sobre as identidades que não se definem por suas permanências (GILROY, 2001; BHABHA, 1998; HALL, 2006; SAID, 2003; SPIVAK, 2014; SANTOS, I., 2008), mas pela capacidade de se reconstituir continuamente, produzindo novas configurações, alternando permanência e mudança ininterruptas.

\section{Caminhos da ciência que nos habita}

Os movimentos que se consolidam nos anos 1980 do século 20 anunciaram um interesse crescente em uma cultura de memória (HUYSSEN, 2000). Esses estudos denunciam o apagamento das memórias por meio, tanto da produção midiática, quanto da produção de esquecimentos pela hiperexposição desses grupos. Nesse aspecto, o excesso é escassez, levando à apatia e à incapacidade de conectar passado-presente-futuro, capturados em um presente sem fim. Esse fenômeno foi amplamente estudado por Benjamin (1994), na tentativa de compreender que há uma falência da capacidade de compartilhar experiências, e que reinvestir no detalhe, no valor do mínimo, poderia ser um caminho para o reinvestimento nessas experiências e suas trocas. 
A memória se organiza na vivacidade da história de seus agentes, em diálogo com o narrador e sua realidade socio-histórica. Diálogo tenso e pertinente aos estudos da psicossociologia, pois narrador, sociedade e história se fazem de modo imbricado. A memória como campo e objeto de estudos é a memória social (SÁ, 2007), já que pelo mergulho na vida cotidiana e suas memórias, podem-se compreender aspectos de uma sociedade e de seu tempo.

Não há como destituir a memória e o esquecimento de seus aspectos políticos, que reinventam tempo e lugar, denunciando o interesse crescente em histórias que resistem em silêncio ou de modo silencioso (POLLAK, 1989) à onda globalizante. Estes grupos reconhecem e se reconhecem a partir de valores e saberes próprios, que desafiam a cultura hegemônica de ocidentalização do mundo fixada na relação com o Norte Global (NEGRI; COCCO, 2005). Nesse movimento, se reconhece que a memória como categoria dinâmica, se atualiza a partir de suas próprias narrativas, como uma memória viva, atualizada pelo presente e sempre no presente (POLLAK, 1992; PERALTA, 2007; SÁ, 1984).

No que se refere aos povos e comunidades tradicionais (COSTA; ALVARENGA, L.; ALVARENGA, A, 2007; SANTOS, A., 2015), as vivências, memórias e experiências têm sido preservadas e transmitidas com estratégias próprias, num movimento contracolonial, produzindo saberes que organizam o mundo e sua cosmovisão, em oposição, como pertencentes a outros legados que não os hegemônicos. Se parece difícil a abstração desta proposição, o conflito reside no fato de que a concepção de ciência que aprendemos e discutimos em nossas práticas tem suas bases no legado colonial e, nesse sentido, cabe aqui a reflexão de que na academia, estamos sempre tratando de pensar e repensar estes valores. O pós-colonialismo e o giro decolonial servem de amparo para compreender e reinventar nossa ciência, mas não os saberes tradicionais, pois estes desde sempre estão em movimento de resistência em constante desafio a esses valores. Quando a academia se dedica e investe na composição de forças com essas vozes insubmissas à ciência hegemônica, cabe o desafio de novas epistemologias, como posição política na constituição de outros modos de pensar e revitalizar o campo das ciências como um espaço plural e interepistêmico (COSTA, 2018; CARVALHO, 2017) pela voz dos mestres dos saberes tradicionais, pautados na oralidade, na circularidade e nos saberes ancestrais que sobreviveram à escravização e seus desdobramentos.

O pós-colonialismo, como ferramenta para compreender os efeitos do colonialismo, investiu na revitalização das Epistemologias do Sul, de povos, cujas vozes usualmente eram invisíveis e silenciosas (SAID, 2003; SILVA, 2000; GROSFOGUEL; OSO; CHRISTOU, 2014; HALL, 2014; POLLAK, 1992). Reconhece o conflito inerente à relação com os povos dominadores, tendendo ao apagamento das identidades dos grupos dominados e a reprodução dos paradigmas hegemônicos por diferentes movimentos: a imposição da língua do colonizador, a proibição de expressões religiosas, a definição de padrões estéticos e culturais. Na América Latina este mo- vimento foi considerado por autores como Grosfoguel (2006) como giro decolonial, tomada de referência para elucidar aspectos da experiência colonial a partir de autores da América Latina pela produção de conhecimento próprio, o que produziu um importante arcabouço teórico para a análise e intervenção nas muitas repercussões e complexidades deste processo.

\section{O grupo de sacerdotisas e a proposta de pesquisa}

Pensando um projeto de ciência pautado nos saberes ancestrais e na perspectiva dos poderes e saberes femininos, a pesquisa se estabeleceu com o objetivo de discutir a produção de memórias de mulheres que cultuam a deusa Iyami Osoronga no Rio de Janeiro. A proposta de doutorado surge de um chamado, fruto de muitas confluências. Aqui, destacamos o trabalho com grupos de mulheres em situação de violência doméstica, o ofício de contadora de histórias africanas, um jeito de proporcionar narrativas contra-hegemônicas sobre a África e seus descendentes, que por meio da tradição oral colocam em xeque, de modo sutil, a cristalização de uma África selvagem e sem cultura (NUNES; CARVALHO, 2009). Além desta experiência, o fato de conhecer uma das sacerdotisas da Sociedade Osoronga, por intermédio de uma religiosa, estudiosa da religião, foi o que possibilitou desenhar os pilares iniciais dessa pesquisa, sobre mulheres de uma sociedade secreta, um culto apartado, mas que tem laços com o candomblé, cujas bases remontam aos tempos do Brasil colônia, com a constituição da Irmandade da Boa Morte (BERNARDO, 2005; SANTOS, I., 2008), em Salvador, na Bahia.

Inicialmente, a pesquisa seria pautada na entrevista com as sacerdotisas do culto, uma pesquisa qualitativa (FLICK, 2009) que envolvia a percepção das dimensões do tempo, contextos e pessoas envolvidas no processo. Neste caminho o referencial definido foi a produção de narrativas de vida (THOMPSON, 2002), para organizar os elementos que fossem surgindo e que servissem de ancoragem para a memória e a tradição, ativadas pelo processo de narrar (NORA, 1993; PERALTA, 2007). A pesquisa seria participante (BECKER, 1999), visando promover este diálogo com a garantia de que o grupo se identificaria com o material produzido, desenhando o material produzido.

O trabalho se mostrou bem mais difícil do que imaginávamos. Os primeiros contatos foram indiretos, com a presença em algumas festas no terreiro, quando ocorreram encontros informais com as mulheres que fazem parte do culto a Iyami. Nesses momentos a conversa fluía com uma ou outra integrante do grupo de modo bastante leve, descompromissado, mudando radicalmente quando o assunto era o culto a Iyami e suas vivências como Iyalode(s). No decorrer do processo, cada palavra seria repensada e questionada sempre que havia dúvidas ou equívocos de minha parte, ao apresentar as histórias ouvidas como texto. Entre o narrado e o vivido, o ouvido e o escrito, manifestavam-se várias lacunas, muitas delas propositais, já que se trata de uma investigação sobre o segredo e sobre modos de ouvir e narrar estes segredos, sem revelá-los. 


\section{Por uma ciência que nos caiba}

Se o candomblé tem suas hierarquias, rituais e compromissos, a academia também tem os seus, e no encontro dessas vozes foi se desenhando um novo conflito. Era notório que a participação das mulheres na produção do trabalho extrapolava em muito a ideia de participação. Se a princípio o objetivo era colher as narrativas das sacerdotisas, ficou bem claro que as Iyalode(s) não gostam de falar sobre si e decidiram que seria interessante saber o que algumas pessoas pensam sobre elas e sobre seus poderes; foi assim que identificaram quem seriam as pessoas a serem entrevistadas e construíram as perguntas que julgaram necessárias ao desenvolvimento das entrevistas realizadas nesta ordem: elas por outras, elas por eles, elas por elas.

Nesse formato, as perguntas foram relacionadas aos temas: quem são as sacerdotisas; se há diferença entre elas e as outras mulheres do terreiro; quem são as mais poderosas; se havia ou não conhecimento acerca dos dons que recebem; se foram beneficiado(a)s por algum desses poderes, entre outras. Refazer o percurso a partir das vozes que falam sobre elas foi um processo rico e doloroso, porque em muitos momentos a imaginação apontava modos diferentes dos que foram sendo desenhados na partilha, marcado pelo valor de se dispor a sentar e ouvir segredos. A cada nova entrevista, aumentava o volume de trabalho e a preocupação com os prazos da academia, mas a temporalidade do terreiro, dos tempos sagrados é de outra ordem. Sempre que conversávamos sobre este assunto, ouvia que "o tempo tem o tempo que o tempo tem", "tudo a seu tempo", "Iyami conhece o tempo e sabe cuidar dele". Com isso, não cabia me preocupar com o tempo, mas dar conta de vivê-lo e aproveitar o percurso.

O conceito de "forasteira de dentro" (COLLINS, 2016) foi utilizado para compreender este movimento de nos deixar ficar e reinventar o lugar de pertencimento, num movimento contínuo.

Como uma pesquisa colaborativa, um dos movimentos é sempre se reposicionar diante dos objetivos e compromissos com o grupo e, nesse fazer, um dos pontos nevrálgicos foi a presença de um co-orientador homem escrevendo sobre Iyami. No início do doutorado, esta não era uma realidade que propusesse algum empecilho, ou ao menos não foi pensada como tal, já que todos os envolvidos, orientadora, co-orientador, co-orientadora de campo e doutoranda, estavam engajados em uma direção única, pautada nos fazeres e saberes próprios aos seus campos de estudo e experiências. Antes de realizar entrevistas com as Iyalode(s), ocorreram vários encontros para a produção de narrativas que apresentassem as raízes e as mitologias do culto a Iyami Osoronga no Brasil, sob a perspectiva do grupo, bem como sobre a dinâmica do terreiro e do candomblé, fundamentais para que se compreendesse o contexto mais amplo que envolve a Sociedade Osoronga e seus mistérios. A certa altura ficou claro que, para elas, era inadmissível uma presença masculina na escuta dos segredos sobre Iyami, ainda que, com seus saberes, reconhecessem que ele era "um homem com uma boa energia". Construir um trabalho que reverencia a força e a energia do feminino deveria ser com energias totalmente femininas. Com as respostas fornecidas pelo grupo selecionado pelas Iyalode(s) foi possível conversar com elas, a partir das impressões que os membros da comunidade do terreiro tinham sobre elas.

\section{Considerações finais}

Falar sobre o segredo provoca imenso desconforto. Nossa tradição acadêmica tem como mote detalhar e analisar todas as dobras dos acontecimentos, lançando luz aos detalhes, modo de dar a conhecer no fazer científico. Nesse trabalho, ficou explícito que as nuances do segredo têm papel fundamental na sobrevivência dos valores e saberes do grupo. O mistério é uma constante no que se refere ao que pode ser escrito sobre o grupo, sobretudo, no interior da comunidade de terreiro. Alguns dos entrevistados (as) desconheciam quase completamente a dinâmica e as integrantes do grupo.

Pautado na tradição passada "de boca a ouvido", o trabalho valorizou o encontro único daqueles que se dispõem a ouvir as histórias em segredo; e mais do que ouvir, usar ouvidos de escutar. A escrita dessas memórias representou a reconfiguração de modos de fazer ciência, uma ciência que é contra-hegemônica por se propor a uma equivalência de saberes, um reposicionamento constante de nossos modos de produção de conhecimento. A tradição permite a perpetuação e transmissão de valores e saberes ancestrais, mas pautada em uma ética que não pode ser corrompida pelo fazer acadêmico. E se nós, muitas vezes não nos damos conta de que existe correlação forte entre a transmissão desses saberes e a preservação de seus segredos, neste trabalho, este tem sido um ponto fundamental.

Os objetivos se ampliaram para a proposição de um olhar sobre o modo com que a Sociedade Osoronga é vista pelo seu próprio círculo de relação, explicitando que as hierarquias e mistérios do grupo estão preservados, enquanto a narrativa em relação ao universo de Iyami Osoronga se propaga.

A pesquisa traz para o campo da psicossociologia um caminho para o diálogo com grupos e saberes extramuro, levando a produção de modos de fazer pesquisa, pautados no reconhecimento e valorização dos saberes tradicionais e, sobretudo, das limitações da própria ciência como representante da forma exemplar de apresentação do mundo. As transformações se deram em nível macro, interferindo nos modos de pensar a pesquisa, a ciência e de fazer ciência, já que aprender a ouvir sobre o segredo foi também um exercício de aprender a guardar segredos e, em nível micro, como um modo muito particular de aprender sobre os poderes femininos, modos de usar e guardar poderes, sobre formas de construir uma relação de colaboração em pesquisa, através dos saberes compartilhados, mas muito disso ficará como segredo. 
Informações sobre as autoras:

Silvia Barbosa de Carvalho

iD https://orcid.org/0000-0003-3533-9859

(9) http://lattes.cnpq.br/5837383252387336

Mestre em Ciências da Saúde pela Escola Nacional de Saúde Pública/Fundação Oswaldo Cruz (2000). Psicóloga formada pela UERJ (1993), Especialista em Saúde Pública (ENSP/Fiocruz/1997), Pós-Graduada em Culturas Africanas e Afrobrasileiras (Atlântica Educacional/UCB/2007), contadora de histórias, membro fundadora do Grupo Karingana ua Karingana: Ouvindo e contando histórias africanas(2005). É Psicóloga da UFRJ desde 2008, atualmente na Coordenação de Políticas de Saúde do Trabalhador/Seção de Educação e Promoção da Saúde/UFRJ(2010), onde coordena o Projeto Narrativas, Literatura e Saúde do Trabalhador, voltado para ações de cultura e saúde no ambiente de trabalho. Doutoranda do Programa EICOS - Psicossociologia de Comunidades e Ecologia Social/UFRJ. Membro do Grupo de Pesquisa LABMems - Laboratório de Memórias, territórios e Ocupações, rastros sensíveis, EICOS/UFRJ.

\section{Samira Lima da Costa}

iD https://orcid.org/0000-0003-4891-0436

\section{(9) http://lattes.cnpq.br/1253895144833105}

Atualmente é professora Associado I do Departamento de Terapia Ocupacional (FM/CCS) e do Programa de Pós-Graduação em Psicossociologia de Comunidades e Ecologia Social (IP) da UFRJ. Tem atuado, lecionado, orientado e pesquisado sobre as relações entre memória, território, cultura, comunidades e ocupação. Áreas de interesse: Psicossociologia; Terapia Ocupacional Social; Políticas Públicas Sociais; Ocupações Tradicionais; comunidades em vulnerabilidade social, papel social da universidade. Possui graduação em Terapia Ocupacional pela Universidade Federal de São Carlos (1995), especialização em Saúde Pública pela Universidade Federal de São Carlos (1996), mestrado em Educação pela Universidade Federal de São Carlos (2000) e doutorado em Psicossociologia de Comunidades e Ecologia Social pela Universidade Federal do Rio de Janeiro (2007). Estágio pós doutoral em Antropologia, no PPGAS da UnB (2017). Foi Professora na Universidade Federal de São Paulo entre 2008 e 2014. É professora colaboradora do Programa de Pós Graduação em Educação em Saúde da UNIFESP-BS e do Programa de Pós Graduação em Antropologia Social da UnB. É líder do Grupo de Pesquisa Laboratório de Memórias, Territórios e Ocupações: Rastros Sensíveis, DGP/CNPq/UFRJ desde 2015; e membro do Grupo de Pesquisa do CNPq "Comunidades, Meio Ambiente e Desenvolvimento - UFRJ"; desde 2005, com pesquisas voltadas para atenção comunitária, valorização da memória local e impactos do desenvolvimento.

\section{Andrea Coelho Ferreira}

\section{(iD) https://orcid.org/0000-0002-0101-3589}

\section{(9) http://lattes.cnpq.br/6302455856715030}

Possui graduação em Direito pelo Centro Universitário Augusto Motta (2002). Mestranda do Programa de Pós-Graduação em Psicossociologia de Comunidades e Ecologia Social do Instituto de Psicologia da UFRJ. Tem experiência na área de Direito, com ênfase em Direito familiar e sucessões e Direito imobiliário. Experiência de mais de dez anos nas áreas de Violência Doméstica, Lei Maria da Penha, Plano de Segurança Pessoal e Estatuto da Criança e do Adolescente e superação do racismo. Responsável pelo espaço Égbé Omi Aje, grupo que desde 2005 coordena ministrando aulas e oficinas em cursos de religiosidade africana, cultura, religião e mitologia Yoruba, para iniciados e não iniciados.

\section{Contribuições das autoras}

Todos as autoras colaboraram ao longo do processo, desde a elaboração até a revisão final do manuscrito. As autoras aprovaram o manuscrito final para publicação.

\section{Como citar este artigo:}

\section{ABNT}

CARVALHO, Silvia Barbosa de; COSTA, Samira Lima da; FERREIRA, Andrea Coelho. Notas sobre pesquisa colaborativa com sacerdotisas da Deusa Iyami Osoronga. Fractal: Revista de Psicologia - Dossiê Psicologia e epistemologias contrahegemônicas, Niterói, v. 31, n. esp., p. 214-219, set. 2019. https:// doi.org/10.22409/1984-0292/v31i_esp/29003

\section{APA}

Carvalho, S. B., Costa, S. L., \& Ferreira, A. C. (2019, set.). Notas sobre pesquisa colaborativa com sacerdotisas da Deusa Iyami Osoronga. Fractal: Revista de Psicologia - Dossiê Psicologia e epistemologias contra-hegemônicas, 31(esp.), 214-219. doi: https:// doi.org/10.22409/1984-0292/v31i_esp/29003

\section{Referências}

BANDEIRA, Hilda Maria M. B. et al. Pesquisa colaborativa: multirreferenciais e práticas convergentes. Teresina/Piauí: EDUFPI, 2016.

BECKER, Howard S. Métodos de pesquisa em ciências sociais. 4 ed. São Paulo: Hucitec, 1999.

BENJAMIN, Walter. O narrador: considerações sobre a obra de Nikolai Leskov. In: Magia e técnica, arte e política. 7 ed. São Paulo: Brasiliense, 1994. v. 1, p. 197-221. Coleção Obras Escolhidas.

BENISTE, José. ÒrunÀiyé: o encontro de dois mundos. Rio de Janeiro: Bertrand Brasil, 1997.

BERNARDO, Teresinha. O Candomblé e o poder feminino. Rever: Revista de Estudos da Religião, n. 2, p. 1-21, 2005. Disponível em: https:/www.pucsp.br/rever/rv2_2005/p_ bernardo.pdf. Acesso em 10 jan. 2016.

BHABHA, Homi K. O local da cultura. Belo Horizonte: UFMG, 1998.

CANCLINI, Nestor Garcia. Culturas híbridas: estratégias para entrar e sair da modernidade. São Paulo: Edusp, 2000.

CARONE, Iray. Breve histórico de uma pesquisa psicossocial sobre a questão racial brasileira. In: CARONE, Iray.; BENTO, Maria Aparecida Silva (Org.). Psicologia social e racismo. 5. ed. Petrópolis/RJ: Vozes, 2012.

CARVALHO, José Jorge de. Uma proposta de estudos culturais na América Latina: inclusão étnica e racial, transdisciplinaridade e encontro de saberes. In: ALMEIDA, Júlia; PATROCÍNIO, Paulo Roberto T. do. (Org.). Estudos culturais: legado e apropriações. Campinas: Pontes, 2017. p. 157-190.

COLLINS, Patricia Hill. Aprendendo com a outsider within: a significação sociológica do pensamento feminista negro. Revista Sociedade e Estado, v. 31, n. 1, jan./abr. 2016. Disponível em: http://www.scielo.br/pdf/se/v31n1/0102-6992-se-31-01-00099. pdf. Acesso em: 17 ago. 2017.

COSTA, Samira. Lima da; ALVARENGA, Luciana; ALVARENGA, Ana Maria. Estudos de/com comunidades tradicionais: cultura, imagem e história oral. Série DOCUMENTA EICOS. Comunidades, meio ambiente, desenvolvimento, n. 17, p. 2, 2007.

COSTA, Samira Lima da. A visão dos mestres e os possiveis da Universidade pluriepistêmica: tradição, território e ocupação. Relatório de pesquisa. Programa de Pós-Graduação em Antropologia Social, Departamento de Antropologia da Universidade de Brasília, Brasília, 2018. 
FLICK, Uwe. Introdução à pesquisa qualitativa. 3. ed. Porto Alegre: Artmed, 2009. Disponível em: http://basessibi.c3sl.ufpr. br/brapci/_repositorio/2015/12/pdf_ba8d5805e9_0000018457. pdf. Acesso em: 22 jul 2018.

GILROY, Paul. O Atlântico negro: modernidade e dupla consciência. Rio de Janeiro. Universidade Cândido Mendes: Centro de Estudos Afro-Asiáticos, 2001.

GOMES, Andrea Caselli. O culto à Iyami Oxorongá nos templos de candomblé: um fenômeno contemporâneo na cidade do Recife. 2015. 146 f. Dissertação (Mestrado em Ciências da Religião) - Programa de pós-graduação da Universidade Católica de Pernambuco, Recife, 2015.

GROSFOGUEL, Ramón. La descolonización de la economia politica y los estúdios postcoloniales: transmodernidad, pensamento fronteirizo y colonialidad global. Tabala Rasa, Bogotá n.4, p 17-48, enero-jun. 2006. Disponible em: http:/ www.scielo.org.co/scielo.php?script=sci_arttext\&pid=S1794$24892006000100002 \& \operatorname{lng}=$ en\&nrm=iso. Acceso: 16 out. 2015

GROSFOGUEL, Ramón; OSO, Laura; CHRISTOU, Anastasia. 'Racism', intersectionality and migration studies: framing some theoretical reflections. Identities: global studies in culture and power, London, v. 22, n. 6, p. 635-652, 2014. https://doi.org/10 .1080/1070289X.2014.950974.

HALL, Stuart. A questão multicultural. In: SOVIK, L. (Org.). Da diáspora: identidades e mediações culturais. Belo Horizonte: UFMG, 2006. p. 56-109.

HALL, Stuart. A identidade cultural na pós-modernidade. Rio de Janeiro: Lamparina, 2014.

HUYSSEN, Andreas. Seduzidos pela memória: arquitetura, monumentos, mídia. Rio de Janeiro: Aeroplano, 2000.

MANZINI, Yaskara. Iyami Osoronga (Minha Mãe Feiticeira): o coletivo feminino na cosmogonia do Universo. 2001. Monografia (Especialização) - Programa de Pós-Graduação Lato Sensu da Faculdade Paulista de Arte, São Paulo, 2001.

NEGRI, Antonio; COCCO, Giuseppe. Glob(AL): biopoder e luta em uma América Latina Globalizada. Rio de Janeiro: Record, 2005.

NORA, Pierre. Entre memória e história: a problemática dos lugares. Proj. História, São Paulo, n. 10, p. 7-28, dez. 1993. Disponível em: http://revistas.pucsp.br/index.php/revph/ article/viewFile/12101/8763.Acesso em: 15 out. 2015.

NUNES, Alyxandra G.; CARVALHO, Silvia B. de. Relato de experiência: a contação de histórias africanas pelo grupo Karinganaua Karinganain. In: BABAWALE, Tunde et al. (Org). Teaching and propagating african and diáspora history and culture. Lagos, Nigéria: Centre for black and african arts and civilization (CBAAC), 2009. p. 735-744.

OGBEBARA, Awofa. Igbadu, a cabaça da existência: mitos nagôs revelados. 2 ed. São Paulo: Pallas, 2006.

PERALTA, Elsa. Abordagens teóricas ao estudo da memória social: uma resenha crítica. Arquivos da Memória: Antropologia, Escala e Memória, n. 2 (Nova Série), p. 4-23, 2007. Disponível em: http://www.fcsh.unl.pt/revistas/arquivosda-memoria/ArtPDF/02_Elsa_Peralta\%5B1\%5D.pdf. Acesso em: 12 mar. 2015.
POLLAK, Michael. Memória, esquecimento e silêncio. Revista Estudos Históricos, Rio de Janeiro, v. 2, n. 3, p. 3-15, 1989. Disponível em: http://www.uel.br/cch/cdph/arqtxt/Memoria esquecimento_silencio.pdf. Acesso em: 10 set. 2013.

POLLAK, Michael. Memória e identidade social. Revista Estudos Históricos, Rio de Janeiro, v. 5, n. 10, 1992. p. 200212. Disponível em: http://bibliotecadigital.fgv.br/ojs/index. php/reh/article/view/1941/1080. Acesso em: 19 nov. 2015.

SÁ, Celso Pereira de. Sobre o campo de estudo da memória social: uma perspectiva psicossocial. Psicologia: Reflexão e Crítica, Porto Alegre, v. 20, n. 2, p. 290-295, 2007. http:// dx.doi.org/10.1590/S0102-79722007000200015.

SÁ, Celso Pereira de. Sobre a fundamentação psicológica da psicologia social e suas implicações para a educação. Fórum educ., Rio de Janeiro, v. 8, n. 1, p. 23-44, jan./mar.1984. Disponível em: http://bibliotecadigital.fgv.br/ojs/index.php/fe/ article/view/60707. Acesso em: 23 set. 2018.

SAID, Edward. W. Orientalismo: o Oriente como invenção do Ocidente. São Paulo: Companhia de Bolso, 2003.

SANTOS, Antônio Bispo dos. Colonização: modos $e$ significação. Brasília: UNB, 2015.

SANTOS, Irinéia, M. Franco. dos. Iá Mi Oxorongá: as mães ancestrais e o poder feminino na religião africana. Sankofa: Revista de História da África e de Estudos da Diáspora Africana, São Paulo, n. 2, p. 59-81, dez. 2008. https://doi. org/10.11606/issn.1983-6023.sank.2008.88730.

SILVA, Tadeu T. (Org.). A produção social da identidade e da diferença. In:__. Identidade e diferença: a perspectiva dos estudos culturais. 6 ed. Petrópolis, RJ: Vozes, 2000. p. 73-102.

SINHORETO, Jaqueline; MORAIS, Danilo de Souza. 2018. Violência e racismo: novas faces de uma afinidade reiterada. Revista de Estudios Sociales, Bogotá, n. 64, p. 15-26, abr. 2018. http://dx.doi.org/10.7440/res64.2018.02.

SPIVAK, Gayatrichakravorty. Can the subaltern speak? In: WILlIAMS, Patrick; CHRISMAN, Laura (Ed.). Colonial discourse and post-colonial theory: a reader. New York: Columbia University Press, 2014. p. 271-313.

THOMPSON, Paul. História oral e contemporaneidade. História Oral, Rio de Janeiro, v. 5, p. 9-28, 2002. Disponível em: http://revista.historiaoral.org.br/index. php?journal=rho\&page=article \&op=view \&path $\% 5 \mathrm{~B} \% 5 \mathrm{D}=47$. Acesso em: 18 nov. 2015.

VERGER, Pierre. Grandeza e decadência do culto de İyàmi Òsòròngà (minha mãe feiticeira) entre os Yorubá. In: MOURA, C. E. M. de (Org.). As senhoras do pássaro da noite. São Paulo: USP/ AxisMundi, 1994. p. 31-71.

VERGER, Pierre. Orixás. Salvador: Corrupio, 1996. 